\title{
Design and Development of Grid-connected Quasi-Z-Source PV Inverter
}

\author{
Zulhani Rasin ${ }^{1}$, Muhammed Fazlur Rahman ${ }^{2}$, Maaspaliza Azri ${ }^{3}$, Md Hairul Nizam Talib ${ }^{4}$, \\ Auzani Jidin 5 \\ 1,3,4,5 Power Electronics and Drives Research Laboratory, Centre for Robotics and Industrial Automation (CeRIA), \\ Fakulti Kejuruteraan Elektrik, Universiti Teknikal Malaysia Melaka \\ ${ }^{2}$ School of Electrical Engineering and Telecommunications, University of New South Wales, Sydney, Australia
}

\begin{tabular}{l} 
Article Info \\
\hline Article history: \\
Received Sep 7, 2018 \\
Revised Oct 18, 2018 \\
Accepted Oct 23, 2018 \\
\hline Keyword: \\
Distributed generation system \\
Grid-connected \\
PV inverter \\
Quasi-Z-source inverter \\
Voltage and current control
\end{tabular}

Article Info

Accepted Oct 23, 2018

\begin{abstract}
An inverter system applied with the PV source typically has a problem of lower input voltage due to constraint in the PV strings connection. As a countermeasure a DC-DC boost converter is placed in between to achieve a higher voltage at the inverter DC link for connection to the grid and to realize the MPPT operation. This additional stage contributes to losses and complexity in control thus reducing the overall system efficiency. This work discussed on the design and development of a grid-connected quasi-Z-source $\mathrm{PV}$ inverter which has different topology and control method compared to the conventional voltage source inverter and able to overcome the above disadvantages. Modelling and performance analysis of the voltage and current controller to achieve a good power transfer from the PV source, as well sycnchronization with the grid are presented in detail. Results from both simulation and experimental verification demonstrate the designed and developed grid-connected qZSI PV inverter works successfully equivalent to the conventional voltage source inverter system.
\end{abstract}

Copyright (c) 2018 Institute of Advanced Engineering and Science. All rights reserved.

\section{Corresponding Author:}

Zulhani Rasin,

Power Electronics and Drives Research Laboratory,

Centre for Robotics and Industrial Automation (CeRIA),

Fakulti Kejuruteraan Elektrik, Universiti Teknikal Malaysia Melaka,

Hang Tuah Jaya, 76100 Durian Tunggal, Melaka, Malaysia.

Email: zulhani@utem.edu.my

\section{INTRODUCTION}

The Z-source inverter (ZSI) [1] as shown in Figure 1(a) is a topology proposed to overcome the drawbacks identified in the existing traditional voltage source inverter (VSI). The main characteristic of the topology is the existence of impedance network formed by the inductors and capacitors between the source of input and the inverter stage. The existence of this impedance network will allow for a situation which is not allowed in the traditional VSI; the shoot-through or short-circuiting of the switches of the same leg at the inverter stage. By intentionally creating the shoot-through situation, the ZSI inverter able to boost the input voltage to produce an output voltage that cannot be achieved by the traditional voltage source inverter.

Among all the newly developed topologies based on ZSI, the Quasi Z-Source Inverter (qZSI) [2] shown in above Figure 1(b) is based on the drawbacks which are available with the original ZSI (specifically the voltage fed ZSI) where the input current is discontinuous during the boost period (shoot-through) and both the capacitors must sustain the high voltage stress. These problems are improved with qZSI, which produces a continuous input current at the input inductor, and a lower voltage stress on one of the capacitor with the same boost ratio. Furthermore, the qZSI topology itself has a common DC rail between the inverter and the input source. In terms of number of components it has the least number of components compared with the other topologies, maintaining two inductors and two capacitors as the original ZSI. This topology has been widely discussed for application in photovoltaic distributed generation system [3]-[8]. 


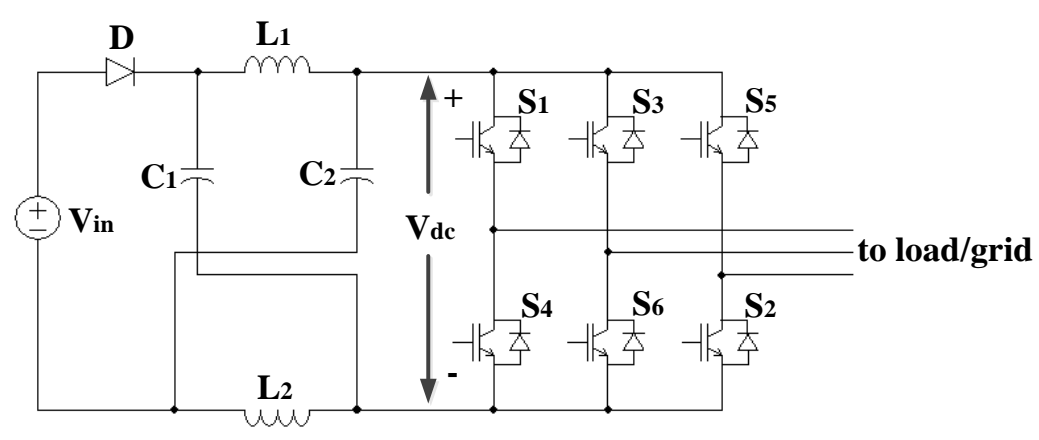

(a)

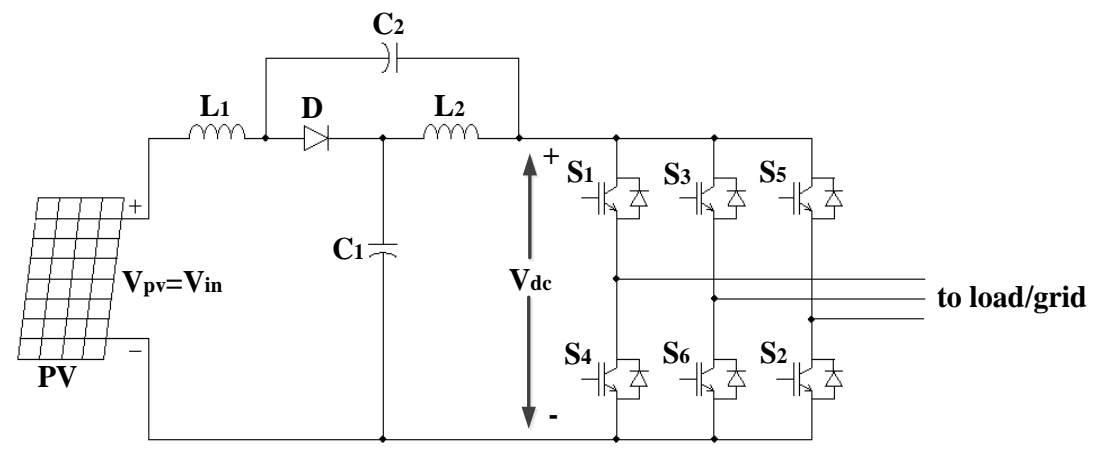

(b)

Figure 1. Topology of (a) Z-source inverter and (b) Quasi-Z-Source inverter

In grid-connected PV inverter system, there are several functions that the system must fulfil; ability to track the maximum power point (MPPT) in order to harvest the maximum power from the solar PV and the ability to realize a voltage and current control for smooth power flow to the load and grid. Li and Anderson [9] are the first to present basic guidelines on the design of parameters for the qZSI which includes the calculation for components rating in dealing with wide input voltage range of the PV for connection with the grid. Based on the provided results through simulation and experiment, it is shown that the inverter able to deal with variation range of input voltage and producing an output voltage suitable for grid connection. However, there is no control element involved for actual implementation of MPPT and to facilitate current flow into the grid.

The work by Park et al. [10]-[11] suggests a new algorithm of MPPT implementation for the gridconnected qZSI and with current control at the point of common coupling (PCC). The MPPT is realized through the adjustment of shoot-through duty ratio, with capacitor voltage controlled at a fixed value. Current control is implemented based on the reference signal given from the difference in capacitor voltage control but no detailed modelling or explanation is provided. The produced simulation and experiment results are also very limited with no indication that the current control is functioning well in grid-connected environment.

Then again Li et al. in [12] - [13] comes with more detailed works on the controller design where the PV inverter system able to function in both standalone mode and grid-connected mode. During standalone mode the output voltage of the inverter is controlled similar to the voltage control in the conventional VSI where the SPWM signal is adjusted according to the feedback from the PI voltage controller. At the DC side, the transfer function relation between capacitor voltage and the shoot-through duty ratio is first established which enable the capacitor voltage to be controlled at a fixed value to stabilize the DC voltage across the inverter switches. In order to improve the controller dynamic with variation in the input voltage, a feed forward component which defines the duty cycle according to the input voltage and capacitor voltage values is added to the controller. The shoot-through signal is combined with the SPWM signal during the zero stages.

In grid-connected mode, similarly the DC side and the AC side are controlled separately. The dynamic relation between capacitor voltage and grid current is established and current is controlled based on the reference signal from the capacitor voltage controller. The inner loop current controller and 
synchronization with the grid is implemented based on the explored conventional method available in the VSI. From the simulation and experiment results, the MPPT works well to track the maximum power with the current flowing to the grid is synchronized with the grid voltage and the capacitor voltage is controlled at constant. There are no results however shown for a variation of input power and how the internal current loop functioning to feed current into the grid.

Other than the implementation in a 3-phase system, implementation in a single phase system is presented by Chun et al. in [14]. It has a similarity with the above works in the sense that the capacitor voltage is used as a reference to control the current to the grid and by making it constant MPPT is implemented by controlling the shoot-through duty ratio. The difference is on the use of resonance controller for the current controller which sufficiently able to track the AC reference grid current while eliminating the steady state error at the chosen resonance frequency. Furthermore, by introducing a modified space vector PWM for insertion of shoot-through during zero states, the number of switching per cycle is reduced and reduction in switching loss can be expected.

All the above works provide the foundation for the implementation of qZSI in grid-connected environment. The use of capacitor voltage to implement the current control to the grid is a better option rather than using the pulsating voltage across the inverter switches which requires a more complex sensor circuitries. Having a separate control for the AC and DC side makes it possible to implement the MPPT and in overall the qZSI based topology works similarly as the other conventional VSI PV inverter system.

In the next section 2, the methodology used in carrying out the work is detailed. Section 3 provides the verification results using both the simulation tool and experimental hardware and the work is concluded in section 4.

\section{RESEARCH METHODOLOGY}

Figure 2 shows the overall system block diagram which consists of several main components. The PV source is the main power supply for the quasi-Z-source inverter which is connected to the grid via a transformer which is optional depending on the level of output from the inverter. Resistive load is used to demonstrate a local power demand and the inverter system is also equipped with a battery energy storage to provide backup for the power demand and store the excess power obtained from the PV array.

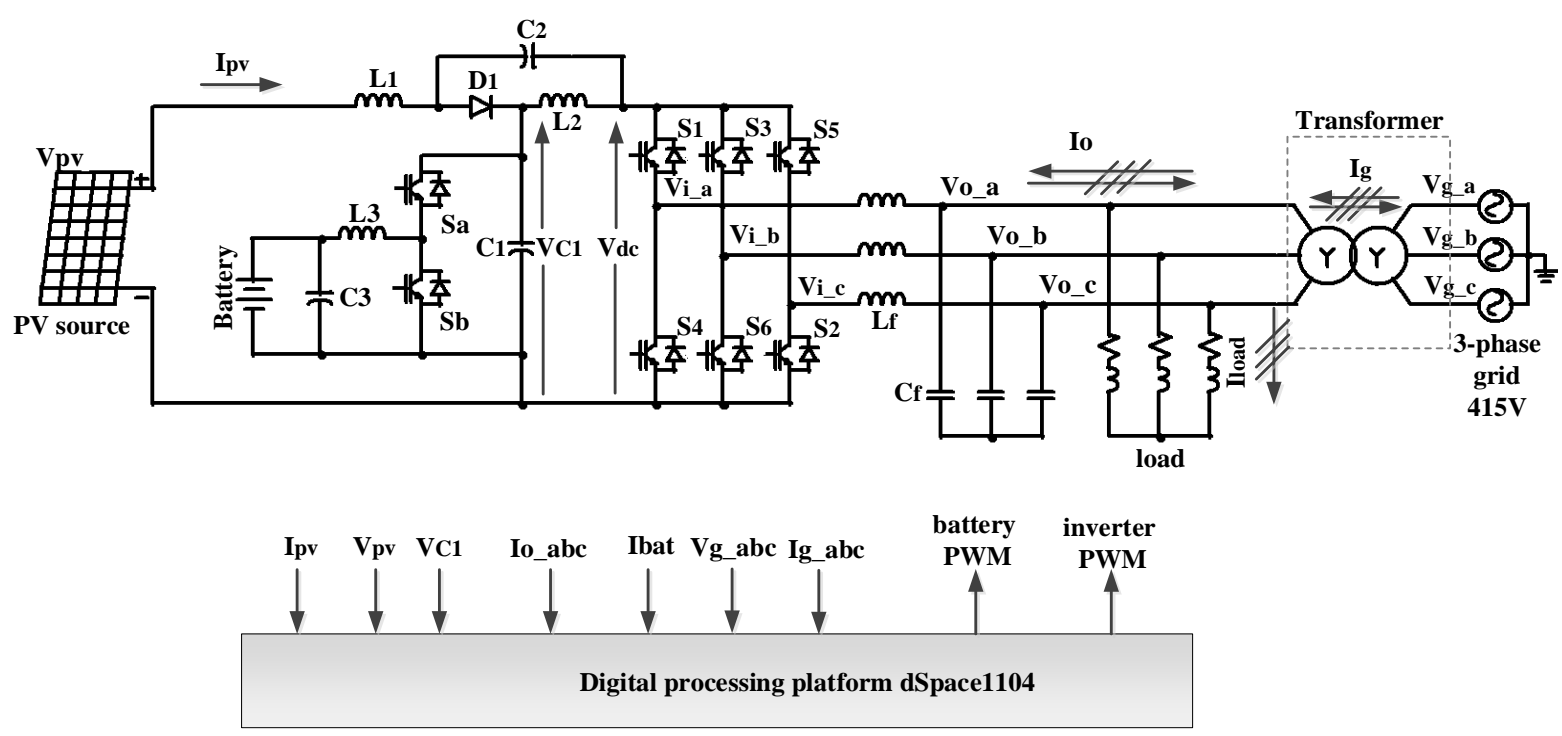

Figure 2. Overall block diagram of the grid-connected qZSI PV inverter system

\subsection{Small Signal Model of qZSI Network}

Small signal model analysis of the qZSI network is necessary to obtain a transfer function that relates various variables in the network to be used for the controller design. Figure 3 shows the small signal model of the qZSI used for the analysis. There are four state variables from the asymmetric qZSI network; current through two inductors $i_{L l}$ and $i_{L 2}$ and the voltage across two capacitors $v_{C l}$ and $v_{C 2}$. Here it is assumed that $C_{1}=C_{2}=C, L_{1}=L_{2}=L$, the stray resistances of inductors $r_{1}=r_{2}=r$ and the equivalent series resistances of 
the capacitors $R_{I}=R_{2}=R$. Switch $S$ represents when the switches of any leg in the inverter is in shoot-through condition.

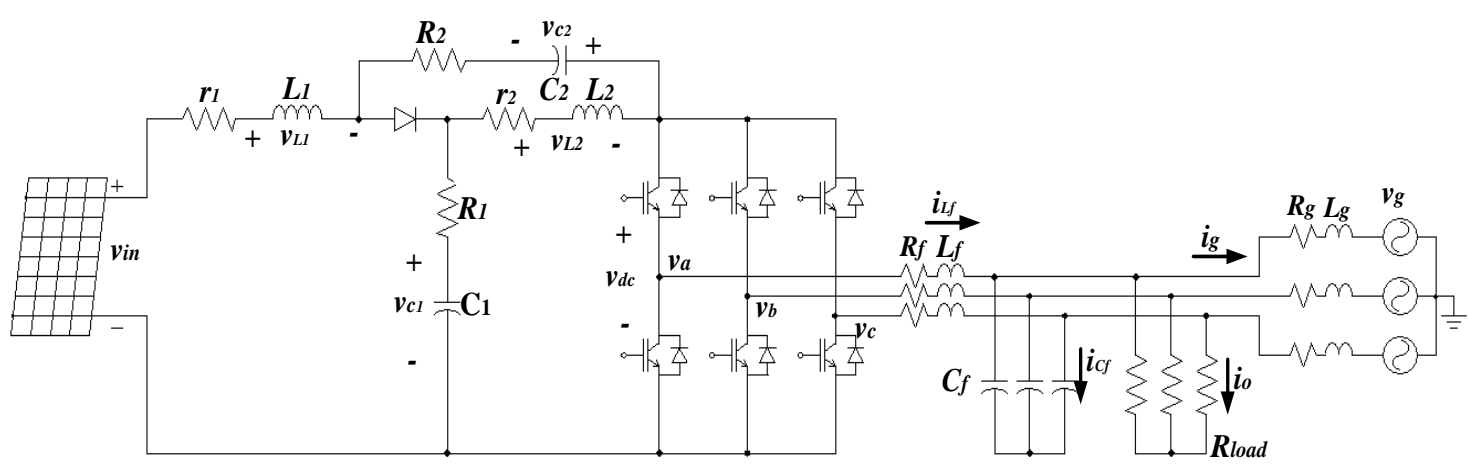

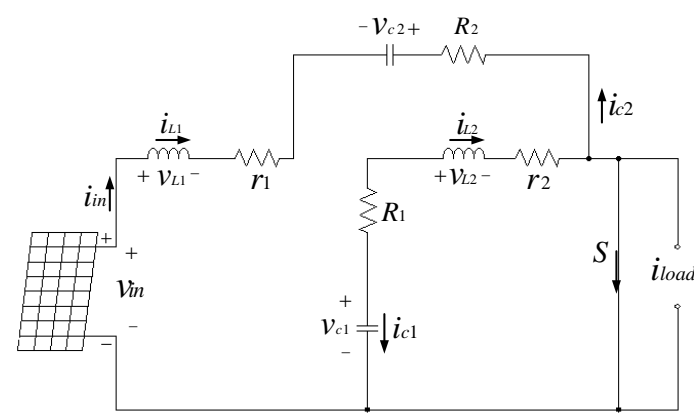

(b)

(a)

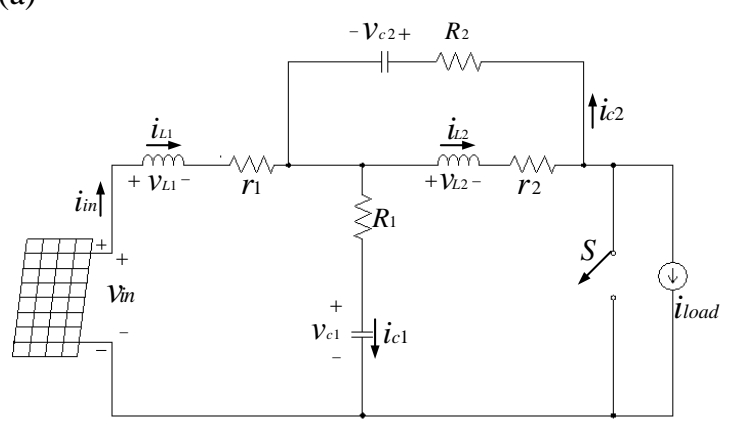

(c)

Figure 3. (a) Model of grid-connected qZSI (b) during shoot-through operation and (c) during non-shootthrough operation

Previous work [4] has discussed on the analysis, and skipped due to space constraint. Transfer function relating between the capacitor voltage $v_{c l}$ and $i_{\text {load }}$ is obtained as follow:

$$
G_{\hat{i}_{\text {load }}}^{\hat{\hat{v}}_{c}}(s)=\left.\frac{\hat{v}_{c}(s)}{\hat{i}_{\text {load }}(s)}\right|_{\substack{\hat{d}(s)=0 \\ \hat{v}_{\text {in }}(s)=0}}=\frac{R\left(1-d_{0}\right)\left(1-2 d_{0}\right)-\left(1-d_{0}\right)(L s+r+R)}{L C s^{2}+C(r+R) s+\left(1-2 d_{0}\right)^{2}}
$$

\subsection{Modelling of the Voltage and Current Control}

The grid-connected qZSI PV inverter system operates in two modes, the standalone mode and the grid-connected mode. The standalone occurs when there is interruption with the grid supply, forcing the inverter system to be cut-off from the grid or if the PV system is installed in no-grid area. During this mode, it is necessary to control the voltage and frequency of the inverter output and the current flow is naturally based on the demand from the load. When the inverter is connected to the utility grid, the inverter output voltage follows the grid voltage and only current control is necessary to ensure a balance power flow between the PV source, load, grid and the battery storage. Expressing the AC side of the qZSI inverter in state space based on Figure 4 below, the following state space equations (2) can be established. $v_{i}$ and $i_{I}$ are the inverter output voltage and current, $L_{f}, C_{f}$ and $r_{f}$ are the LC filter components and its inductor resistance, $v_{o}$ and $i_{o}$ are the voltage and current at the point of common coupling (PCC) with the grid.

In synchronous $d-q$ frame, equations (2) can be expressed as equations (3) and by using the state feedback decoupling control, the inverter output voltage and current control can be described as (4) and Figure 5. As an explanation, when the inverter is in a standalone mode, the voltage at the load side $v_{\text {od }}$ needs to be controlled at reference voltage $v_{o d} *$ and using the PI controller the reference inverter output current $i_{I d} *$ is produced. The flowing inverter output current $i_{I d}$ is controlled to follow the reference current by the PI 
controller which produces reference command voltage $v_{i d} *$ for generating the PWM reference signal. The above explanation also applies for the $q$ component of the $d-q$ frame. In grid-connected mode the voltage at the PCC does not need to be controlled and only current control is implemented to generate the reference command voltage $v_{i d}$.

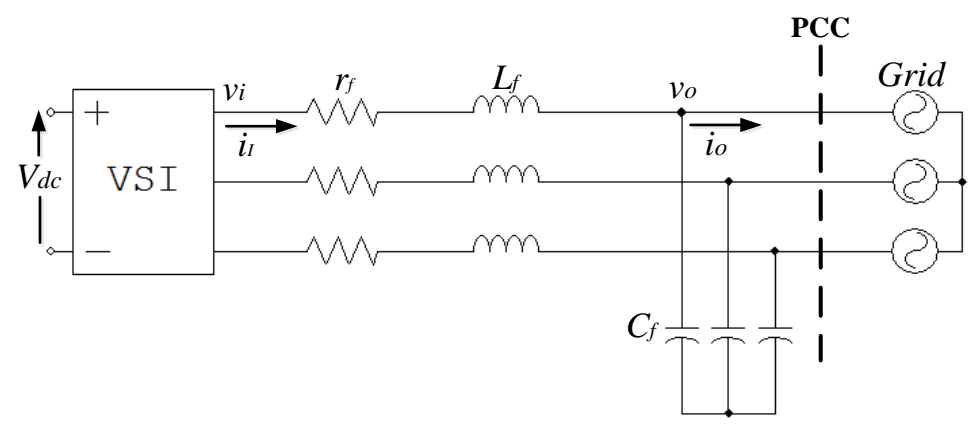

Figure 4. AC side of qZSI inverter

$$
\begin{aligned}
& L_{f} \frac{d}{d t}\left[\begin{array}{l}
i_{I a} \\
i_{I b} \\
i_{I c}
\end{array}\right]=\left[\begin{array}{l}
v_{i a} \\
v_{i b} \\
v_{i c}
\end{array}\right]-r_{f}\left[\begin{array}{l}
i_{I a} \\
i_{I b} \\
i_{I c}
\end{array}\right]-\left[\begin{array}{l}
v_{o a} \\
v_{o b} \\
v_{o c}
\end{array}\right] \\
& C_{f} \frac{d}{d t}\left[\begin{array}{l}
v_{o a} \\
v_{o b} \\
v_{o c}
\end{array}\right]=\left[\begin{array}{l}
i_{I a} \\
i_{I b} \\
i_{I c}
\end{array}\right]-\left[\begin{array}{l}
i_{o a} \\
i_{o b} \\
i_{o c}
\end{array}\right]
\end{aligned}
$$

$L_{f} \frac{d i_{I d}}{d t}=v_{i d}-r_{f} i_{I d}-v_{o d}+\omega L_{f} i_{I q}$

$L_{f} \frac{d i_{I q}}{d t}=v_{i q}-r_{f} i_{I q}-v_{o q}-\omega L_{f} i_{I d}$

$C_{f} \frac{d v_{o d}}{d t}=i_{I d}-i_{o d}+\omega C_{f} v_{o q}$

$C_{f} \frac{d v_{o q}}{d t}=i_{I q}-i_{o q}-\omega C_{f} v_{o d}$

$$
\begin{aligned}
& v_{i d}{ }^{*}=r_{f} i_{I d}+v_{o d}-\omega L_{f} i_{I q}+\left(k_{P}+\frac{k_{I}}{s}\right)\left(i_{I d}{ }^{*}-i_{I d}\right) \\
& v_{i q}{ }^{*}=r_{f} i_{I q}+v_{o q}+\omega L_{f} i_{I d}+\left(k_{P}+\frac{k_{I}}{s}\right)\left(i_{I q}^{*}-i_{I q}\right) \\
& i_{I d}{ }^{*}=i_{o d}-\omega C_{f} v_{o q}+\left(k_{P}+\frac{k_{I}}{s}\right)\left(v_{o d}{ }^{*}-v_{o d}\right) \\
& i_{I q}{ }^{*}=i_{o q}+\omega C_{f} v_{o d}+\left(k_{P}+\frac{k_{I}}{s}\right)\left(v_{o q}{ }^{*}-v_{o q}\right)
\end{aligned}
$$




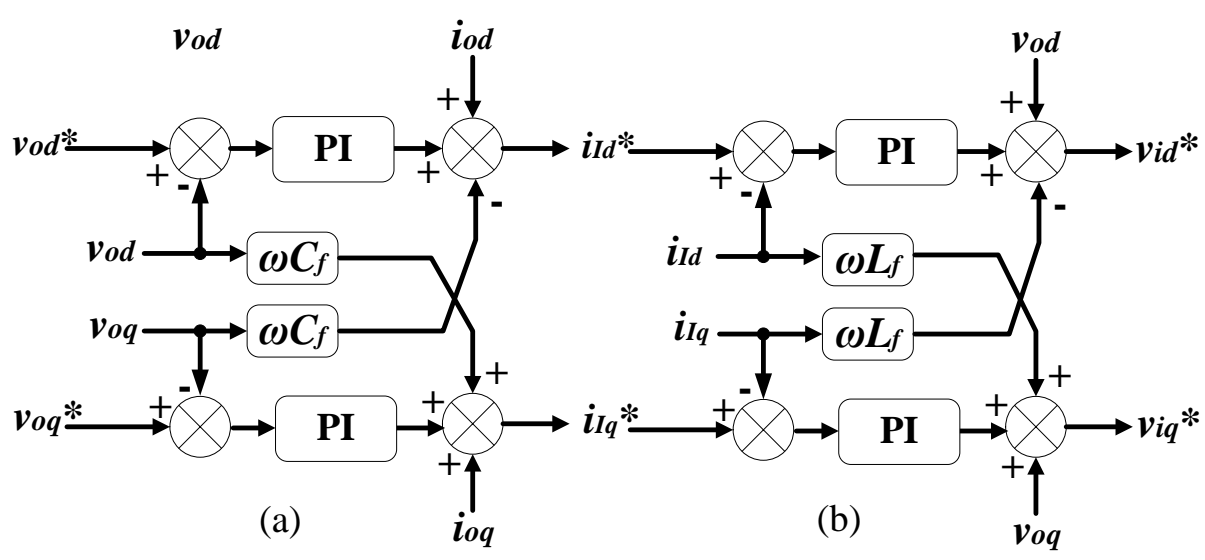

Figure 5. (a) Voltage control and (b) current control of the AC side

According to the instantaneous power theory for balanced three phase system by Akagi [15], a balanced three phase system under sinusoidal condition is defined as a three phase system with equal amplitudes and has $120^{\circ}$ phase difference between all the phases. The instantaneous voltages and currents in the $a b c$ frame with amplitude $V_{m}$ and $I_{m}$ then can be defined as follow.

$$
\begin{array}{ll}
v_{a}=\sqrt{2} V_{m} \sin \theta & i_{a}=\sqrt{2} I_{\mathrm{m}} \sin \theta \\
v_{b}=\sqrt{2} V_{m} \sin \left(\theta-\frac{2 \pi}{3}\right) i_{b}=\sqrt{2} I_{\mathrm{m}} \sin \left(\theta-\frac{2 \pi}{3}\right) \\
v_{c}=\sqrt{2} V_{m} \sin \left(\theta+\frac{2 \pi}{3}\right) i_{c}=\sqrt{2} I_{\mathrm{m}} \sin \left(\theta+\frac{2 \pi}{3}\right)
\end{array}
$$

The active power $P$ and reactive power $Q$ can be defined as equations (6) with its synchronous $d-q$ frame representation in (7).

$$
\begin{aligned}
& P=v_{a} \cdot i_{a}+v_{b} \cdot i_{b}+v_{c} \cdot i_{c} \\
& Q=\frac{1}{\sqrt{3}}\left[\left(v_{b}-v_{c}\right) \cdot i_{a}+\left(v_{c}-v_{a}\right) \cdot i_{b}+\left(v_{a}-v_{b}\right) \cdot i_{c}\right] \\
& P=\frac{3}{2}\left(v_{q} \cdot i_{q}+v_{d} \cdot i_{d}\right) \\
& Q=\frac{3}{2}\left(v_{q} \cdot i_{d}-v_{d} \cdot i_{q}\right)
\end{aligned}
$$

Since the $v_{q}$ component is set to zero at the PLL control, equation (7) becomes equations (8) which implies that the active and reactive power can be controlled independently through $i_{I d}$ and $i_{I q}$ as in the Figure 5.

$$
\begin{aligned}
& P=\frac{3}{2}\left(v_{d} \cdot i_{d}\right) \\
& Q=-\frac{3}{2}\left(v_{d} \cdot i_{q}\right)
\end{aligned}
$$


Figure 6 shows the capacitor voltage and current control mechanism during grid-connected operation. At the DC side of the system, based on the controlled value of capacitor voltage $V_{C l}$, the shootthrough duty ratio $d$ is controlled by the MPPT algorithm in order to regulate the voltage across the PV terminal $V_{p v}$ to achieve the maximum power point according to the following equation (9).

$$
v_{p v}=\frac{1-2 d}{1-d} v_{c 1}
$$

The $V_{C l}$ is controlled at the AC side with a two loops control mechanism; outer loop voltage control of $V_{C I}$ and the inner loop current control. The design of the capacitor voltage PI controller is based on the small signal transfer function relation between $V_{C l}$ and $i_{\text {load }}$ as in equation (1). $i_{\text {load }}$ is obtained through its ratio $G$ with output current at PCC $i_{o}$. The output of $V_{C l}$ controller is the current reference signal $i_{I d \_r e f} *$ which is relayed to the inner loop current control. As for the inner loop current control strategy, a synchronous decoupling current control in two-phase rotating $(d-q)$ frame is applied. The advantage of this control strategy is the three phase symmetric grid voltage and current that can be transformed into a DC variables and by adopting a PI controller, it is possible to realize a no-steady state error adjustment. A feedforward $d$ component of the grid voltage $V_{d}$ is used to improve the controller's dynamic performance. Figure 7 shows the block diagram of the inner loop current control in $s$-domain.

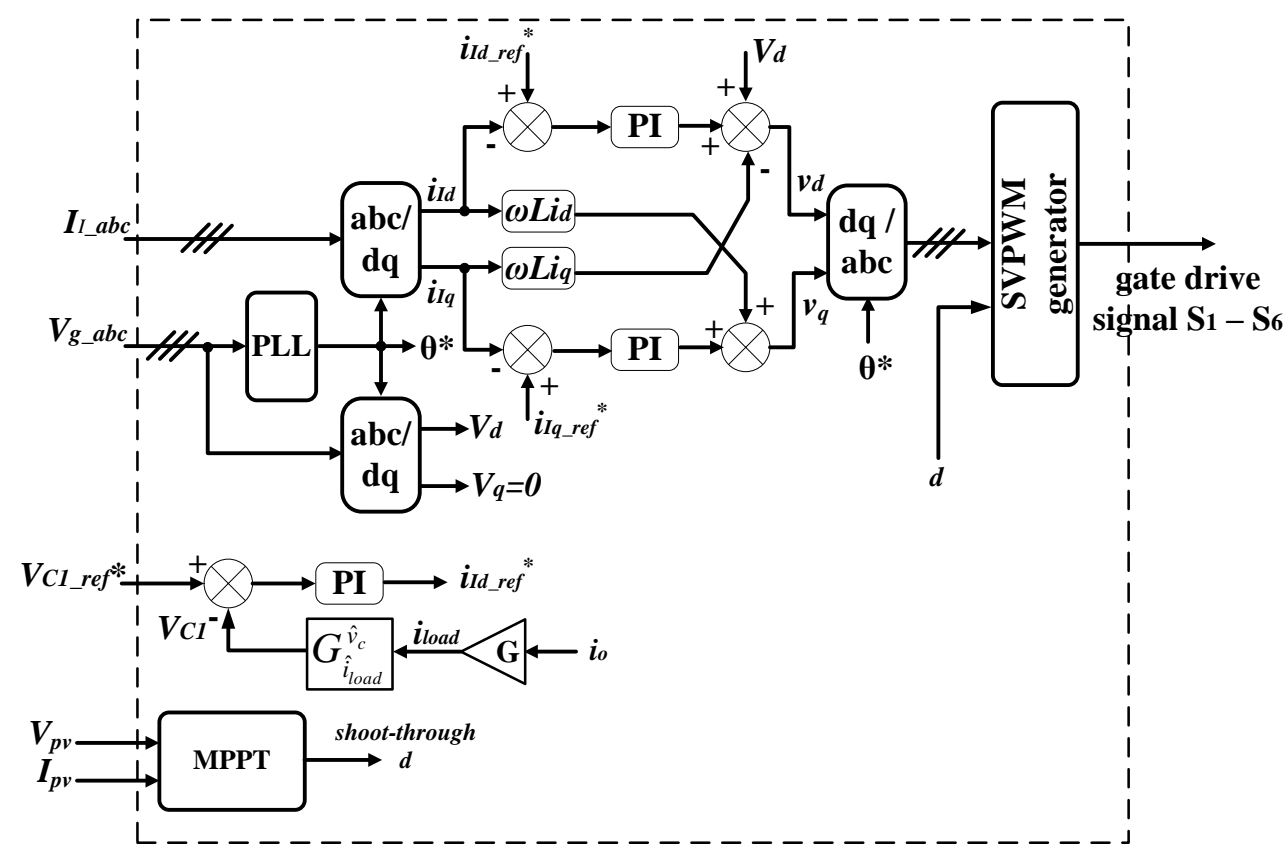

Figure 6. Block diagram of capacitor voltage and inverter output current control in grid-connected mode

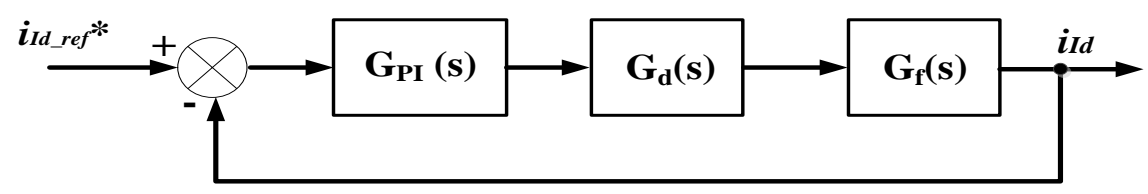

Figure 7. Block diagram of inner loop current control

$G_{P I}(s)$ are the PI controller transfer function, $G_{f}(s)$ is the filter transfer function and $G_{d}(s)$ is the delay caused by the digital computation with $T_{s}$ is the sampling period.

$$
G_{d}(s)=\frac{1}{1+s T_{s}} \quad G_{f}(s)=\frac{1}{s L_{f}+r_{f}}
$$


In designing the controller, it is required to have a stable system and the inner current control is designed to have a shorter settling time to achieve a fast correction and the outer capacitor voltage controller with a slower response. Figure 8 shows the open loop frequency responses analysis for both current and voltage control based on parameters values in Table 1 . Both show a stable system with phase margin bigger that $45^{\circ}$. Figure 9 shows the step response analysis and it is shown that the outer loop voltage response is slower compared to the inner loop current response.

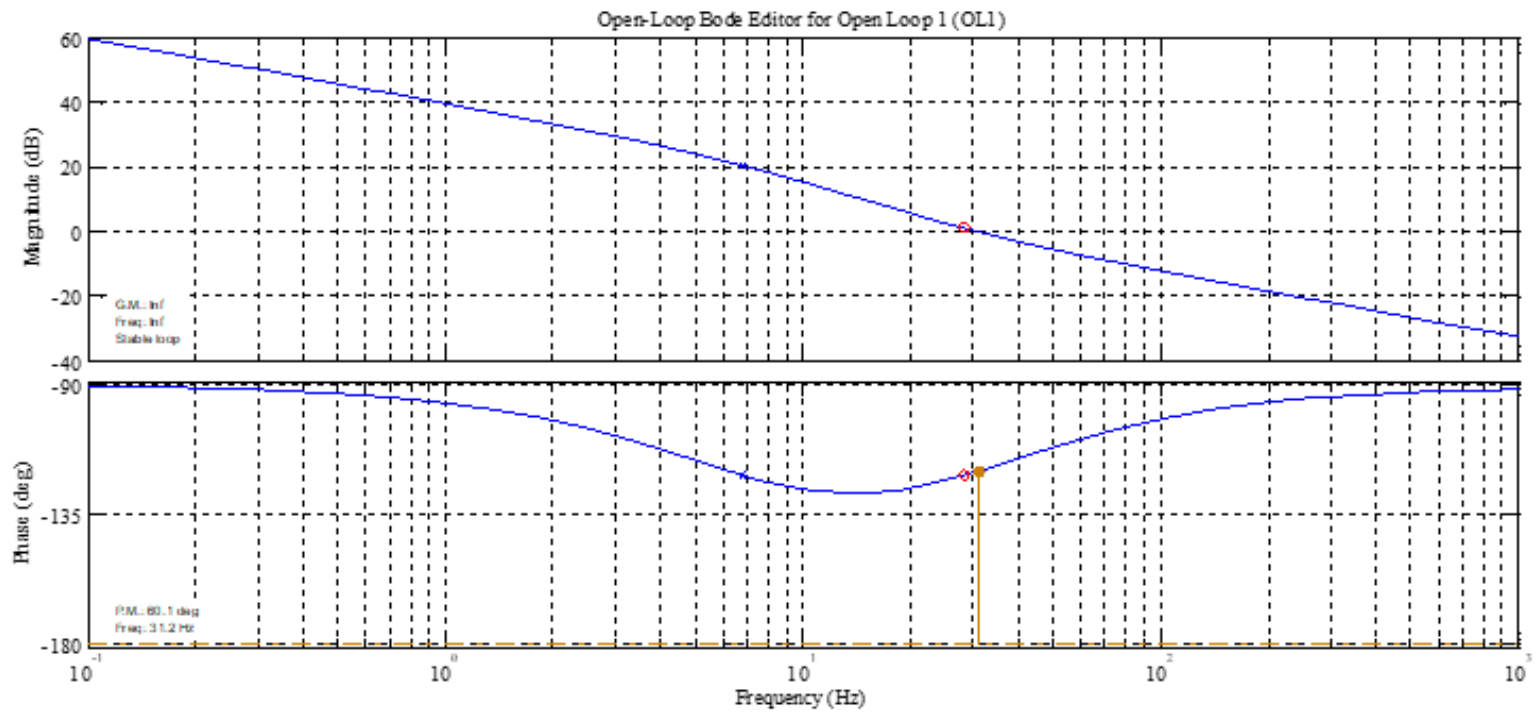

(a)

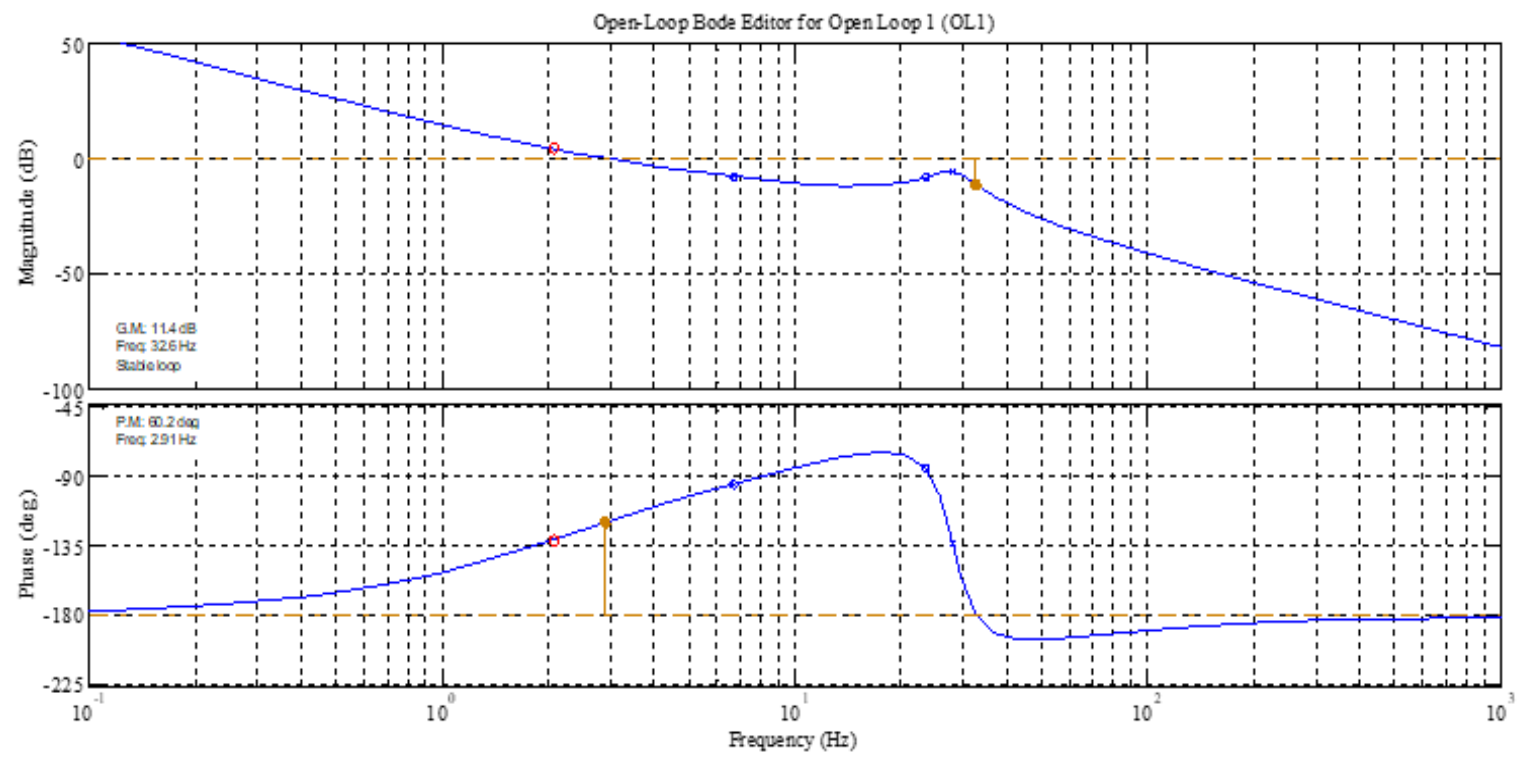

(b)

Figure 8. Open loon bode plot frequency response analysis for (a) inner loop current control and (b) outer loop capacitor voltage control in grid-connected mode

Table 1. Parameters Values for Capacitor Voltage and Current Control Analysis during Grid-connected Mode

\begin{tabular}{ccccc}
$L$ & $C$ & $d$ & $r$ & $R$ \\
\hline $4.7 \mathrm{mH}$ & $1100 \mathrm{~V}$ & 0.3 & $0.2 \Omega$ & $1 \mathrm{~m} \Omega$ \\
\hline
\end{tabular}




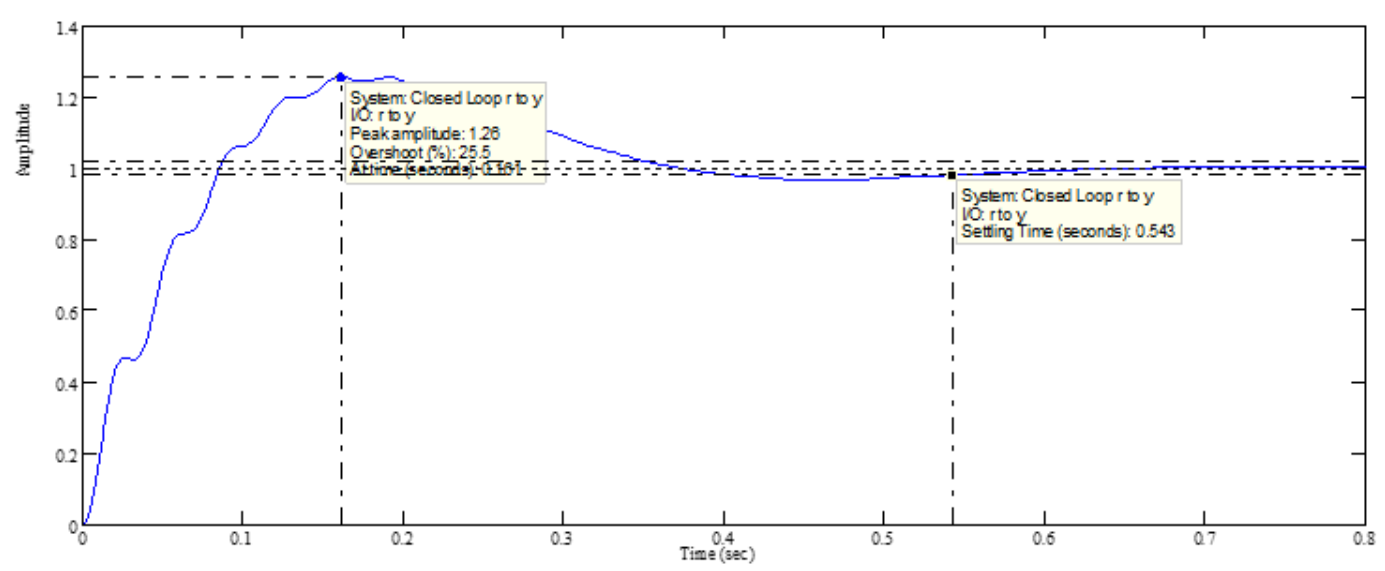

(a)

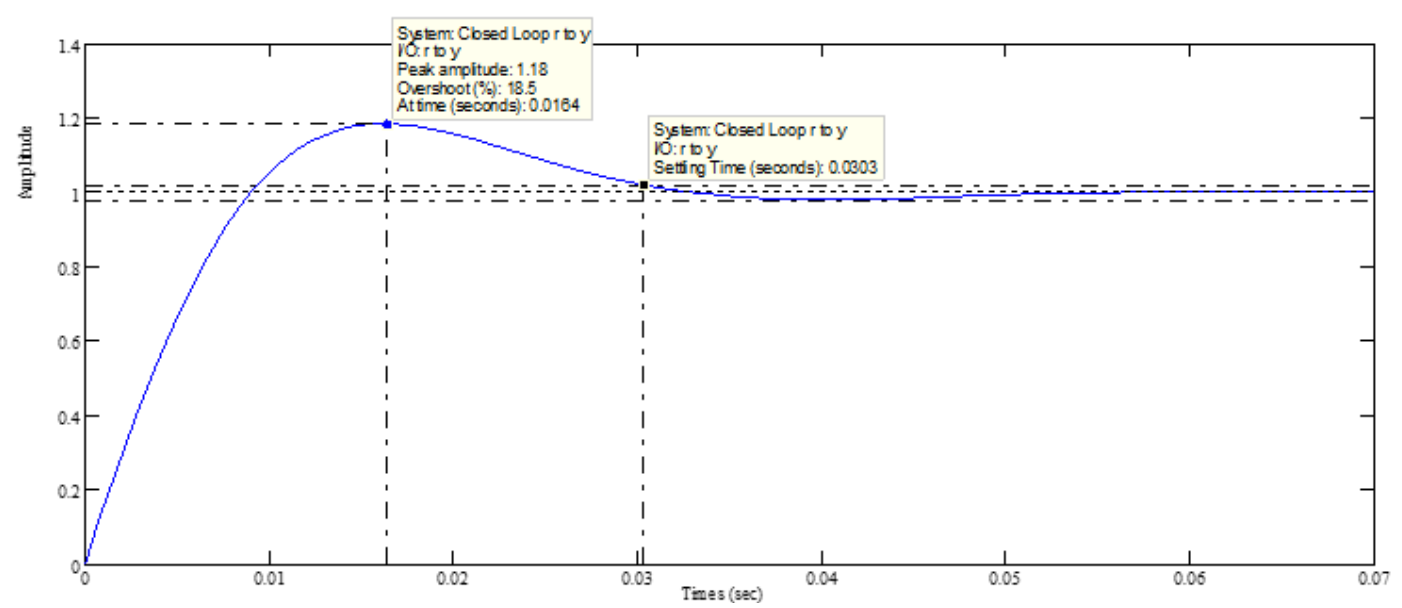

(b)

Figure 9. Step response analysis of the (a) outer loop voltage control and (b) inner loop current control

\subsection{Grid Synchronization}

The phase lock loop (PLL) system is commonly used in grid connected inverter system to ensure synchronization between the grid and the inverter output. This is to make sure a good power factor is achieved in the range specified by the regulation. A basic PLL configuration is shown in Figure 10 [16]. The sensed grid phase voltages $v_{g a}, v_{g b}$ and $v_{g c}$ are firstly transformed into synchronous $d$ - $q$ frame to allow the AC variables represented in DC form, thus the magnitude and phase control can be easily implemented to achieve zero steady state error. The $q$ component of the transformed voltages is controlled at zero and the PI controller produces the frequency $\omega^{*}$ that is integrated to obtain the $\theta^{*}$, which drives the feedback voltage $V_{q}$ to the reference value $V_{q}^{*}$ ref $=0$.

The value $\theta^{*}$ is continuously used for the d-q transformation of the grid voltage which means if the frequency $\omega^{*}$ is identical to the utility grid frequency, the produced waveform is a DC where the $q$ component is zero. As a result the $\theta^{*}$ is always locked to the utility frequency. A feed forward reference $\omega_{f f}=$ $2 \pi f_{g}$ where $f_{g}$ is the grid frequency, is added to the controller output to improve the initial dynamic performance which helps to decrease the starting time of the PLL. 


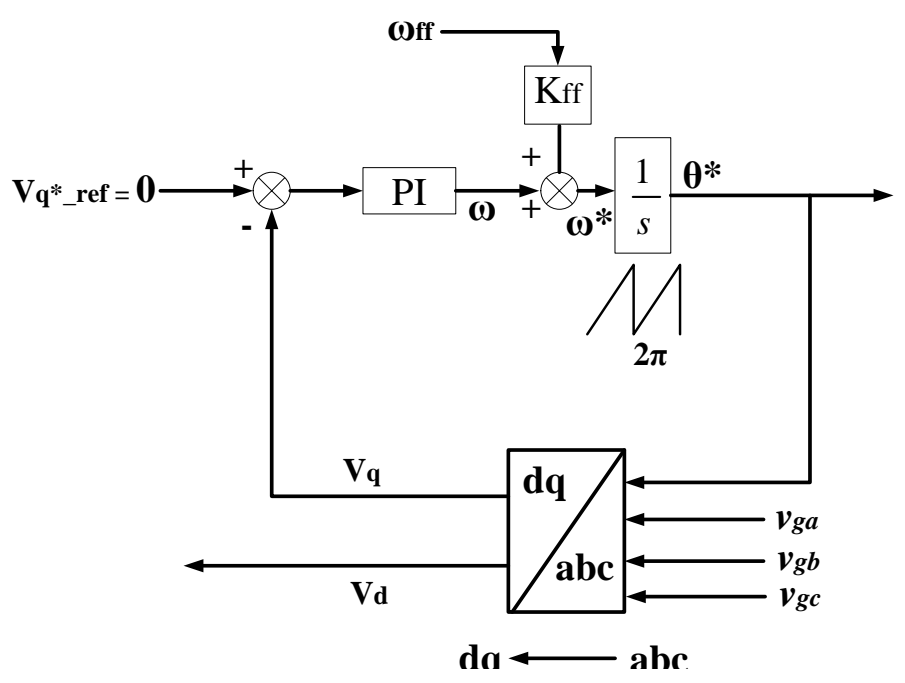

Figure 10. Configuration of PLL

\section{RESULTS AND ANALYSIS}

Based on the system designed and modelled in the previous sections, both the simulation using the Matlab $^{\circledR}$ software and the hardware experiment are carried out with the objective of verifying the operability of the designed grid-connected qZSI PV inverter system. For the simulation, a platform of $5 \mathrm{~kW}$ system is configured to show that it is operable over wide range of power level under residential PV installation category. The PV source configuration is set at $\mathrm{V}_{\text {mpp }} 235.9 \mathrm{~V}$ with the capacitor voltage $V_{C l}$ controlled at 680 $\mathrm{V}$. This makes it possible for direct connection to the 3-phase $415 \mathrm{~V}_{1-1}$ grid. For the experimental platform as shown in Figure 11, the system is scaled down at $0.5 \mathrm{~kW}$ power level with the PV source is configured at $\mathrm{V}_{\text {mpp }} 141.1 \mathrm{~V}$, with capacitor controlled at $200 \mathrm{~V}$ and connection to the 3-phase $415 \mathrm{~V}_{1-1}$ grid is made through a transformer. Table 2 shows the parameters and specifications used for both platforms.

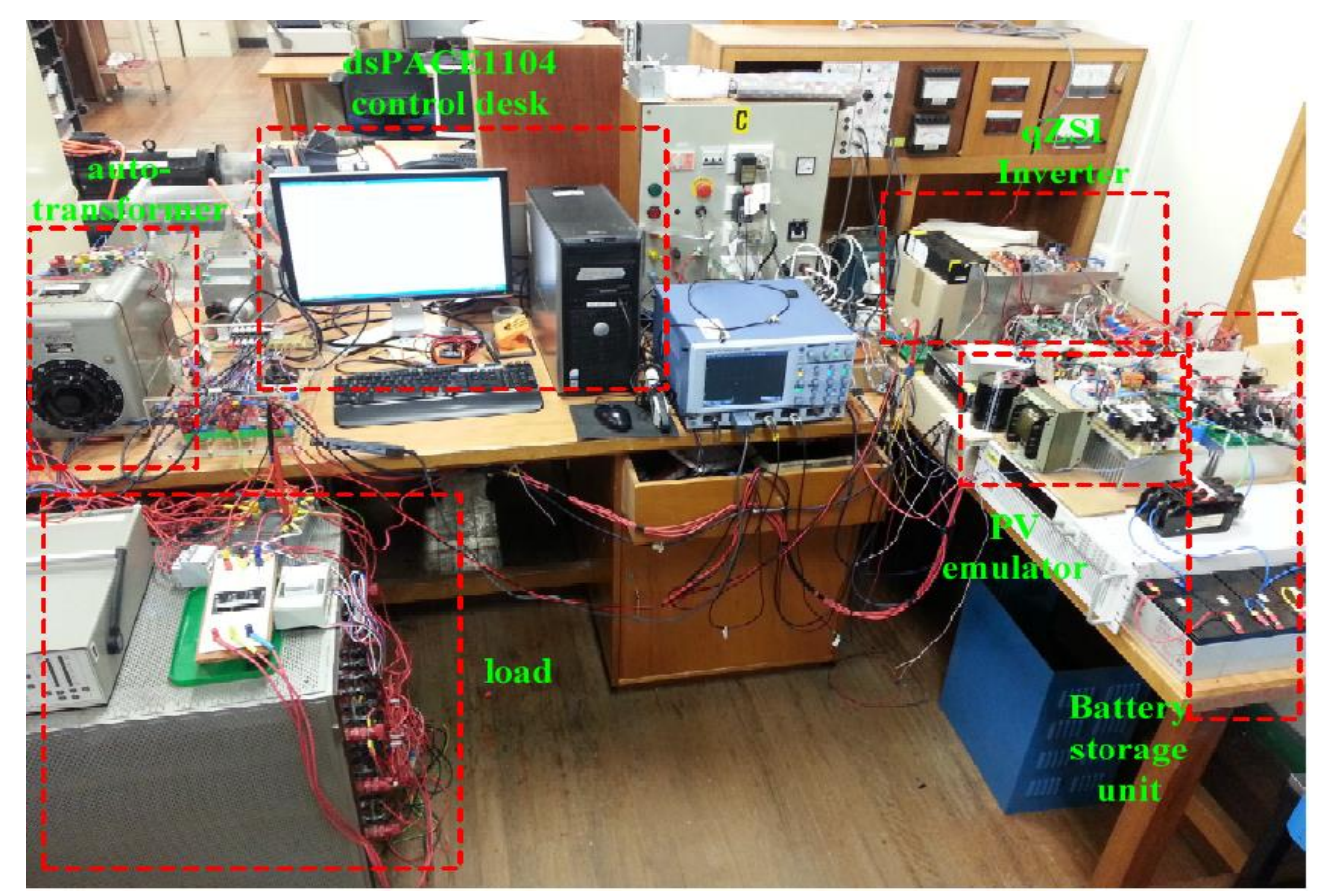

Figure 11. Experimental platform setup at $0.5 \mathrm{~kW}$ power level 
Table 2. Parameters/Specification used for the Simulation and Experimental Setup for Grid-connected PV

\begin{tabular}{|c|c|c|}
\hline Parameters/Specification & $5 \mathrm{~kW}$ configuration (simulation) & $0.5 \mathrm{~kW}$ configuration (experimental) \\
\hline Max power from PV & $5 \mathrm{~kW} V_{m p p}=235.9 \mathrm{~V} I_{m p p}=21.36 \mathrm{~A}$ & $0.5 \mathrm{~kW} V_{m p p}=141.1 \mathrm{~V} I_{m p p}=3.6 \mathrm{~A}$ \\
\hline Max power to grid & $5 \mathrm{kVA}$ & $0.5 \mathrm{kVA}$ \\
\hline DC bus voltage & $\begin{array}{l}V_{C l} \text { controlled at } 680 \mathrm{~V}, V_{d c} 1126-1148 \mathrm{~V}_{\mathrm{pk}} \\
\text { shoot-through } d: 0.39-0.41\end{array}$ & $\begin{array}{c}V_{C I} \text { controlled at } 200 \mathrm{~V}, V_{d c} 258-279 \\
\mathrm{~V}_{\mathrm{pk}} \\
\text { shoot-through } d: 0.2-0.3\end{array}$ \\
\hline Switching frequency $\mathrm{f}_{\mathrm{sw}}$ & \multicolumn{2}{|c|}{$10 \mathrm{kHz}$} \\
\hline Grid connection & transformerless 3-phase $415 \mathrm{~V}_{\mathrm{l}-1 \_r m s}$ & $\begin{array}{c}\text { with transformer } \\
\text { 3-phase } 104 \mathrm{~V}_{1-1 / \text { rms }}: \text { 3-phase } 415 \mathrm{~V}_{\text {l-1 rms }}\end{array}$ \\
\hline Grid filter & \multicolumn{2}{|c|}{$L_{f}=10 \mathrm{mH}, C_{f}=8 \mathrm{uF}$} \\
\hline qZSI network & $L_{l}=L_{2}=4.7 \mathrm{mH}, \quad C_{1}=C_{2}=1000 \mathrm{uF}$ & $L_{l}=L_{2}=4.7 \mathrm{mH}, \quad C_{1}=C_{2}=800 \mathrm{uF}$ \\
\hline Battery storage unit & Lead Acid $20 \times 12 \mathrm{~V}$ in series, $42 \mathrm{Ah}$ & Lead Acid $6 \times 12 \mathrm{~V}$ in series, $7 \mathrm{Ah}$ \\
\hline
\end{tabular}

\subsection{Simulation Results at $5 \mathrm{~kW}$}

Figure 12(a) shows the successful control of capacitor voltage $V_{C l}$ at $680 \mathrm{~V}$ while power from the $\mathrm{PV}$ source is varied between $1 \mathrm{~kW}$ to $5 \mathrm{~kW}$. This is achieved through the current control operation shown in Figure 12(b) where the inverter output current $I_{s d}$ is tracking the reference value from the capacitor voltage controller $I_{\text {ref. }}$. Since all the output current is fed to the grid without a load in between, the reactive component $I_{s q}$ is controlled at 0 . The three phase output current of the inverter is well proportional to the power fed to the inverter.
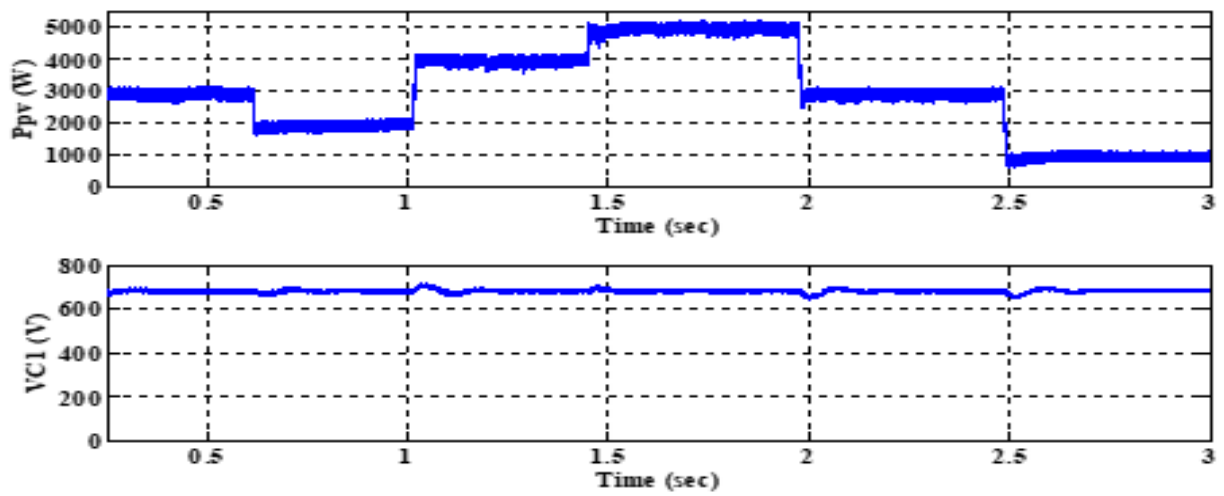

(a)
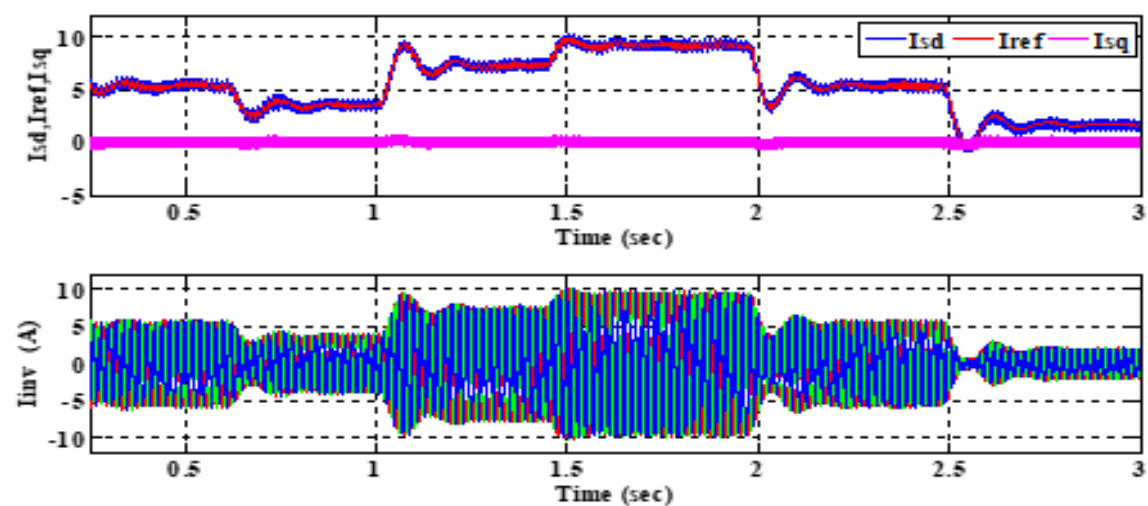

(b)

Figure 12. (a) The power fed by the PV source $P_{p v}$ (top) and the control of capacitor voltage $V_{C l}$ (bottom) (b)

The current control of the inverter (top) and the corresponded 3-phase inverter output current (bottom)

As shown in Figure 13(a), the 3-phase grid voltage is detected using the PLL algorithm and the angle $\theta$ between 0 to $2 \pi$ radian is produced, with time length synchronized with one cycle period of the grid voltage. For synchronization of the inverter output voltage with the grid voltage, the $\theta$ value is applied in the 
current control algorithm. As shown in Figure 13(b), the produced active phase current is in-phase with the grid voltage.
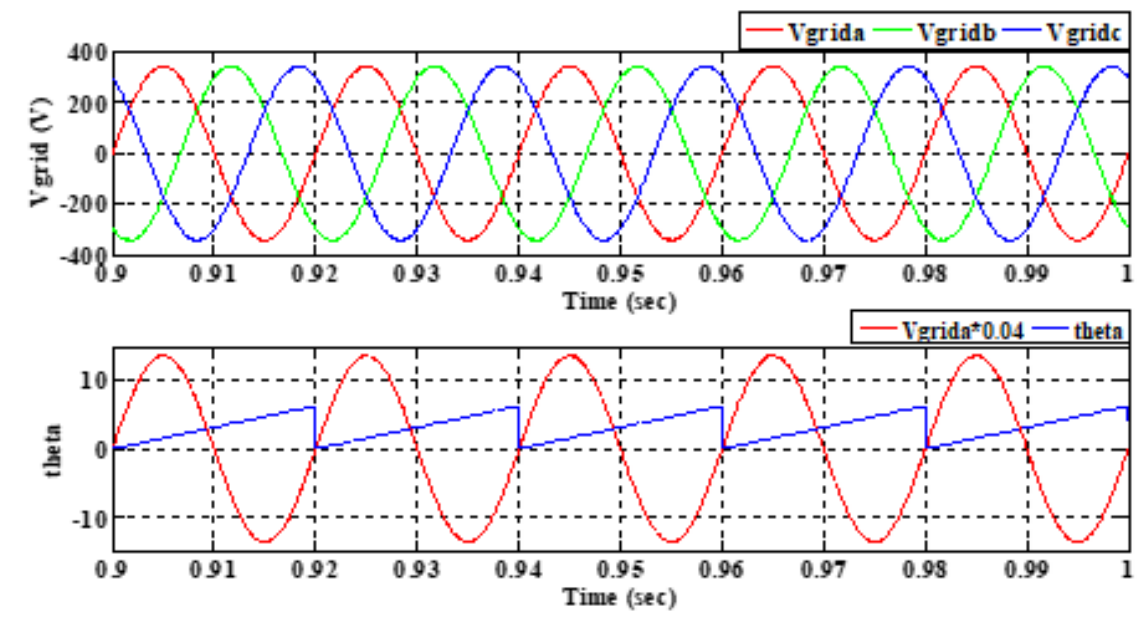

(a)

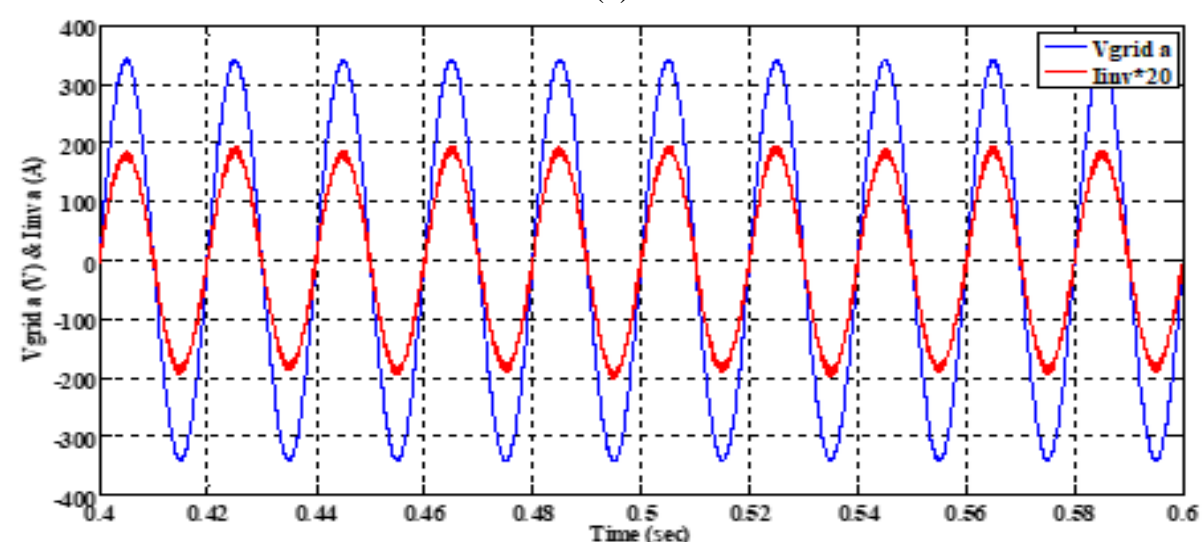

(b)

Figure 13. (a) 3-phase grid voltage $\mathrm{V}_{\text {grid }}$ (top) and the angle $\theta$ produced for synchronization (b) active inverter output phase current of the inverter in-phase with the grid voltage

\subsection{Experimental Results at $0.5 \mathrm{~kW}$}

In grid-connected mode, as shown in Figure 14, capacitor $C_{l}$ voltage $V_{C l}$ is controlled at $200 \mathrm{~V}$ to realize the MPPT operation through the control of the inverter output current. Based from results, when power from the PV source is increasing from $300 \mathrm{~W}$ to $500 \mathrm{~W}$, the active current $d$ component of the inverter output current $I_{s d}$ is successfully controlled to follow the $V_{C l}$ controller's output reference signal $I_{\text {ref }}$ shown in Figure 14(a). The same goes for the case when PV power is decreasing as shown in Figure 14 (b). For both situation since only active power is flowing to the grid, the reactive current $q$ component of the inverter output current $I_{s q}$ is controlled at 0 . The power produced by the PV source goes into the inverter and output current of the inverter $I_{i n v}$ is proportional to the input power from the PV source output in Figure 14 (a) - (b), as shown in Figure 15. 

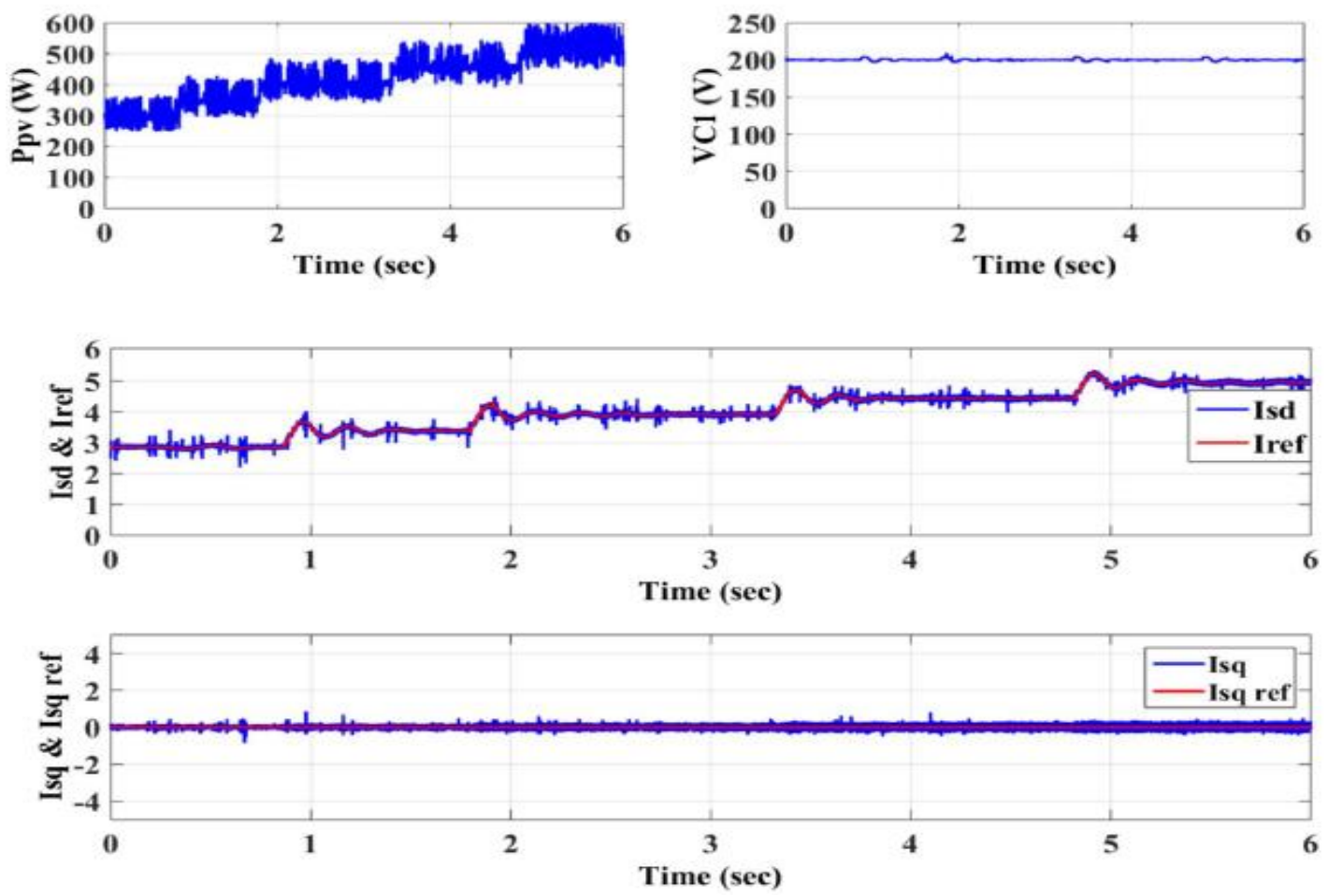

(a)
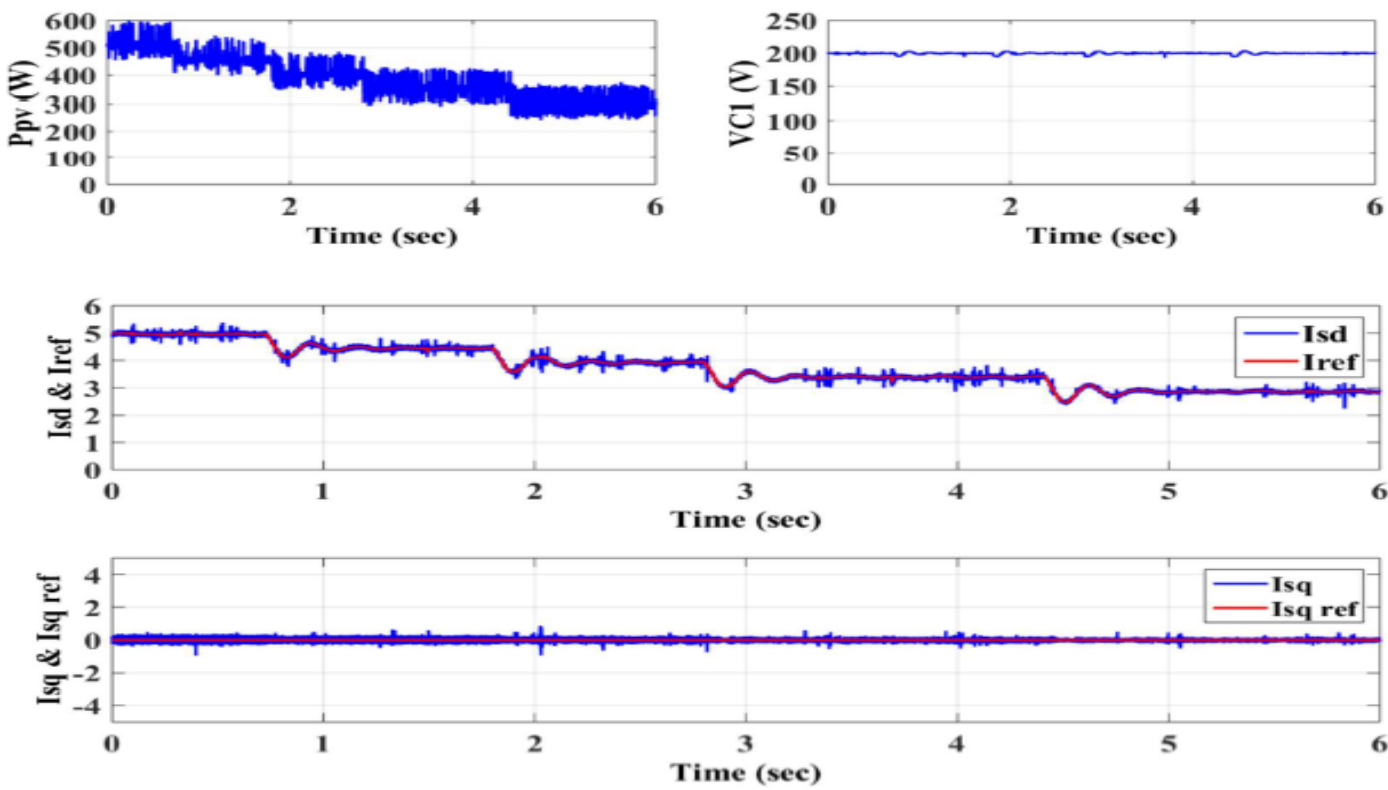

(b)

Figure 14. (a) Capacitor voltage $V_{C l}$ and current $d$ - $q$ control with $P_{p v}$ increasing from $300 \mathrm{~W}$ to $500 \mathrm{~W}$ (b) Capacitor voltage $V_{C l}$ and current $d$ - $q$ control with $P_{p v}$ decreasing from $500 \mathrm{~W}$ to $300 \mathrm{~W}$ 


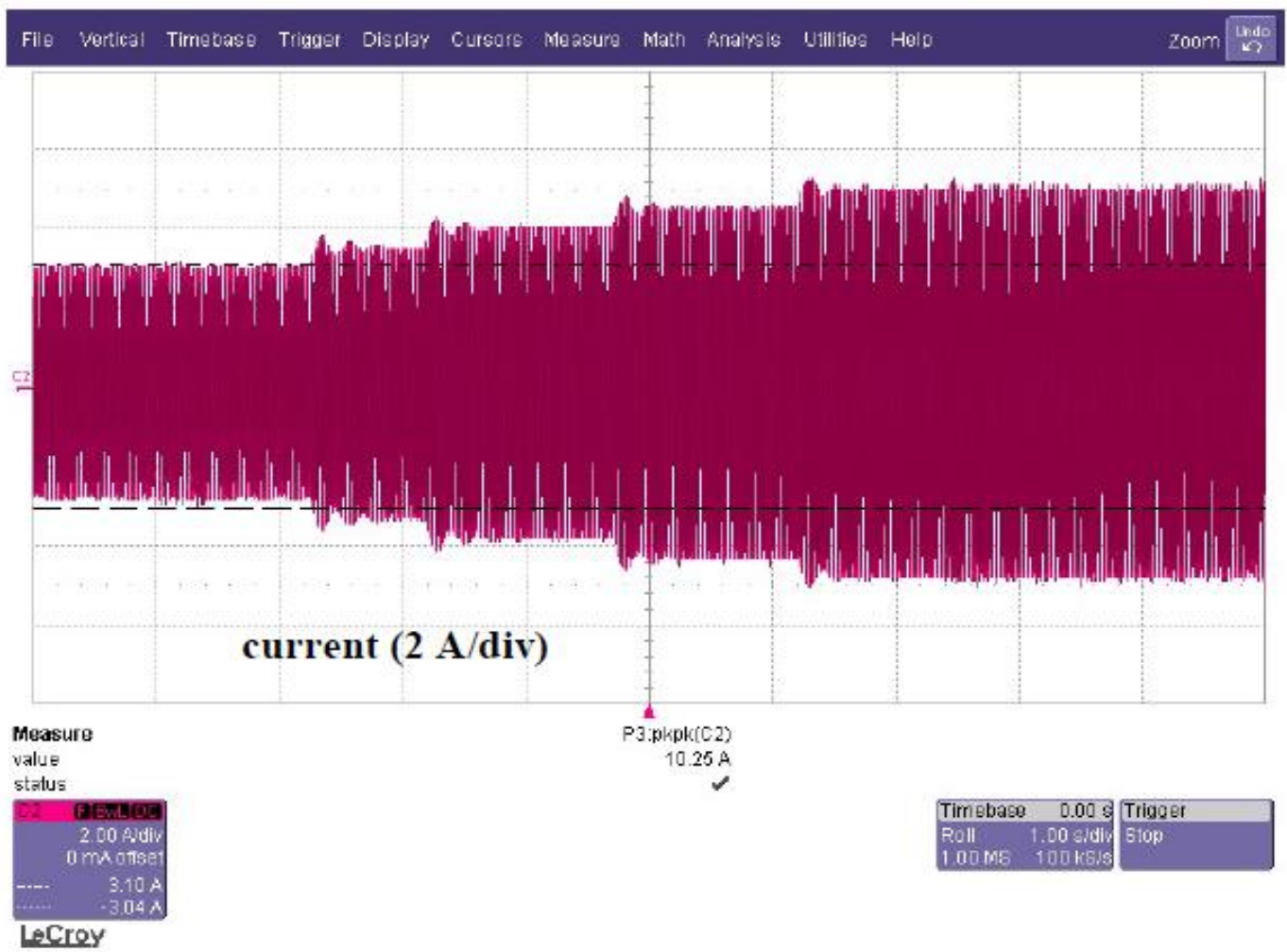

(a)

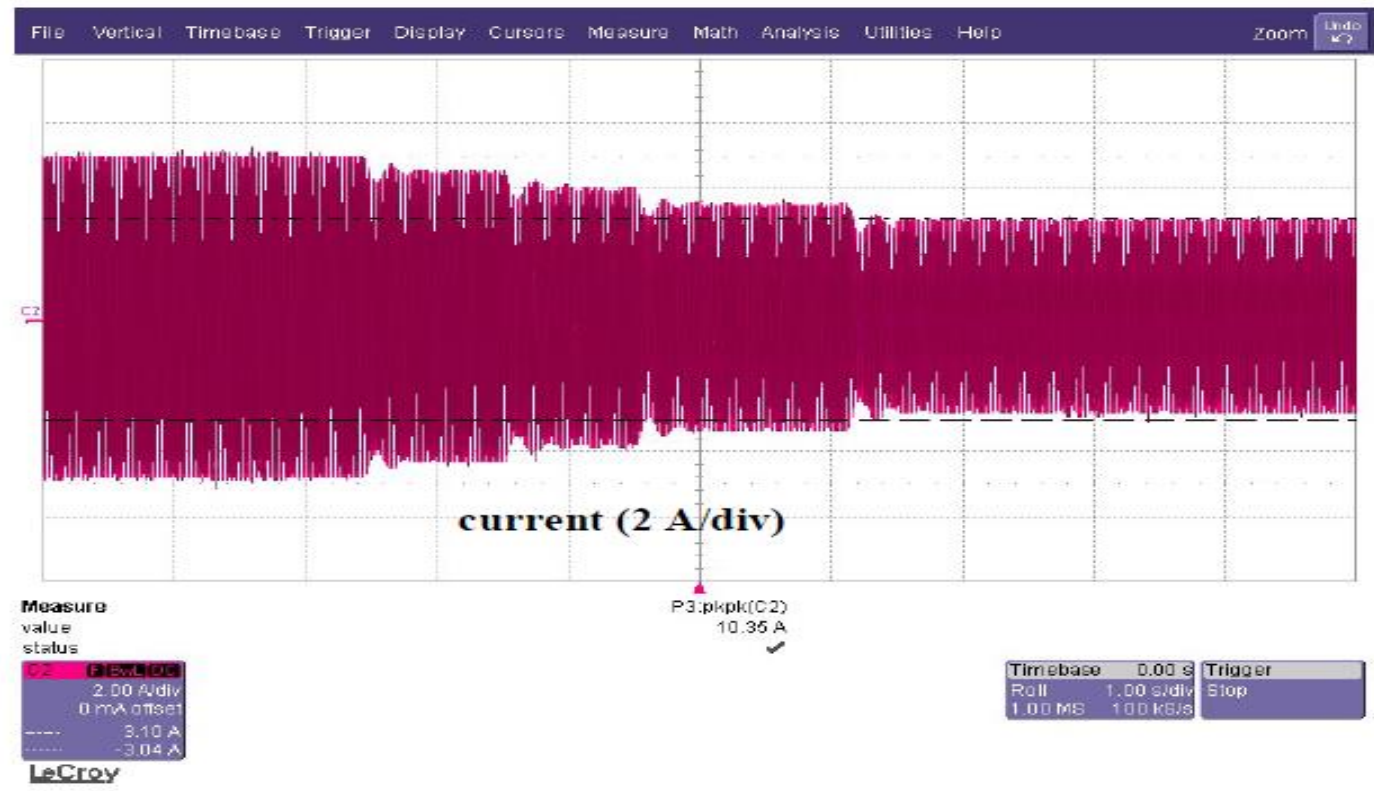

(b)

Figure 15. Variation of inverter output phase current $I_{i n v}$ as PV source is increased and decreased (a) $300 \mathrm{~W}$ to $500 \mathrm{~W}$ (b) $500 \mathrm{~W}$ to $300 \mathrm{~W}$

In grid-connected mode, it is important the inverter output is well synchronized with the grid voltage. The grid line-to-line voltage $V_{l-l}$ of $103.92 \mathrm{~V}_{\mathrm{pk}}$ is firstly measured through the sensor and the corresponding $30^{\circ}$ shifted value of each phase voltage $\mathrm{V}_{\text {phase-pk }}$ of $60 \mathrm{~V}_{\mathrm{pk}}$ is calculated and produced as shown in Figure 16(a). Inside the PLL algorithm the synchronous $d-q$ transformation is carried out with the $q$ component controlled at zero and integration of controller's output is the angle theta $\theta$ which is synchronized with the grid phase voltage shown in Figure 16(b) (top). This $\theta$ is used in the formation of the 3-phase 
sinusoidal control signal as in Figure 16(b) (middle) before producing the SVPWM reference signal for triggering the inverter switches as in Figure 16(b) (bottom). Based from the results, the PLL is operating satisfactorily. With the inverter is injecting power to the grid, the produced inverter output current is almost in phase with the grid voltage at power factor 0.95 as shown in Figure 17.
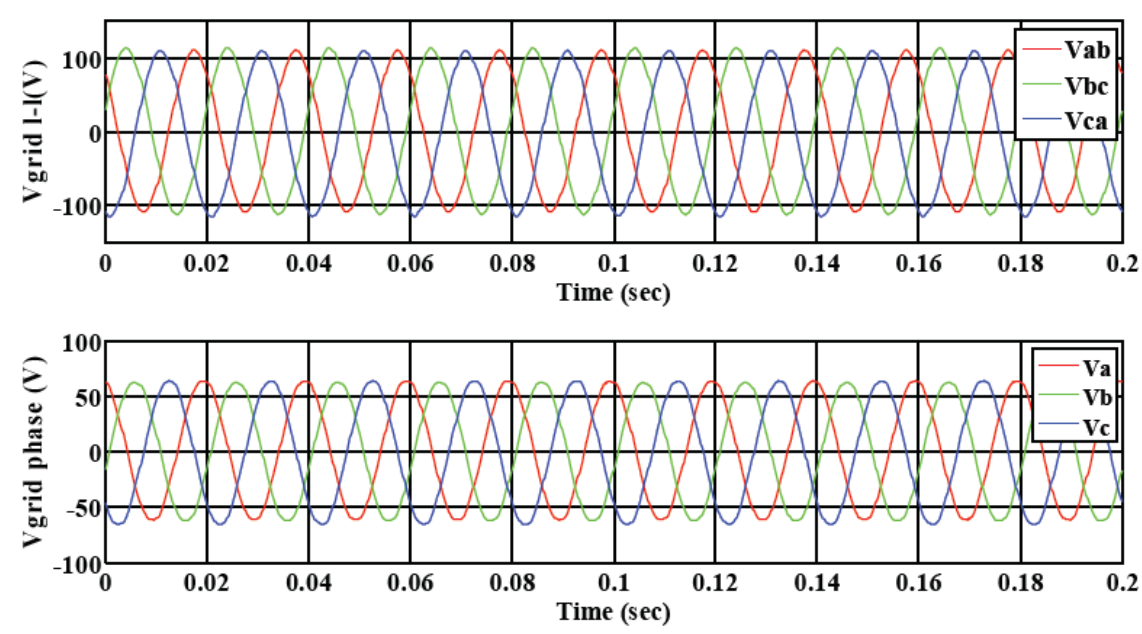

(a)

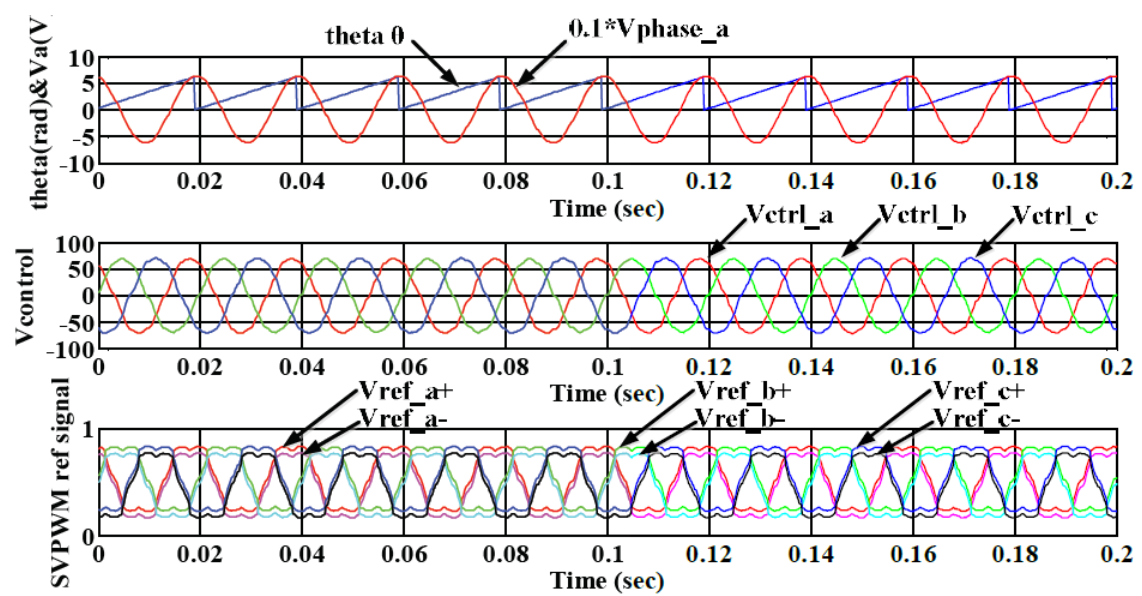

(b)

Figure 16. (a) The line-to-line voltage $V_{l-l}$ of the grid measured by sensor at $103.92 \mathrm{~V}_{\mathrm{pk}}$ and the produced phase voltage $V_{\text {phase }}$ at $60 \mathrm{~V}_{\mathrm{pk}}$ (b) The theta $\theta$ produced by PLL (top), the produced 3-phase sinusoidal control signal (mid) and the SVPWM reference signal (bottom) 


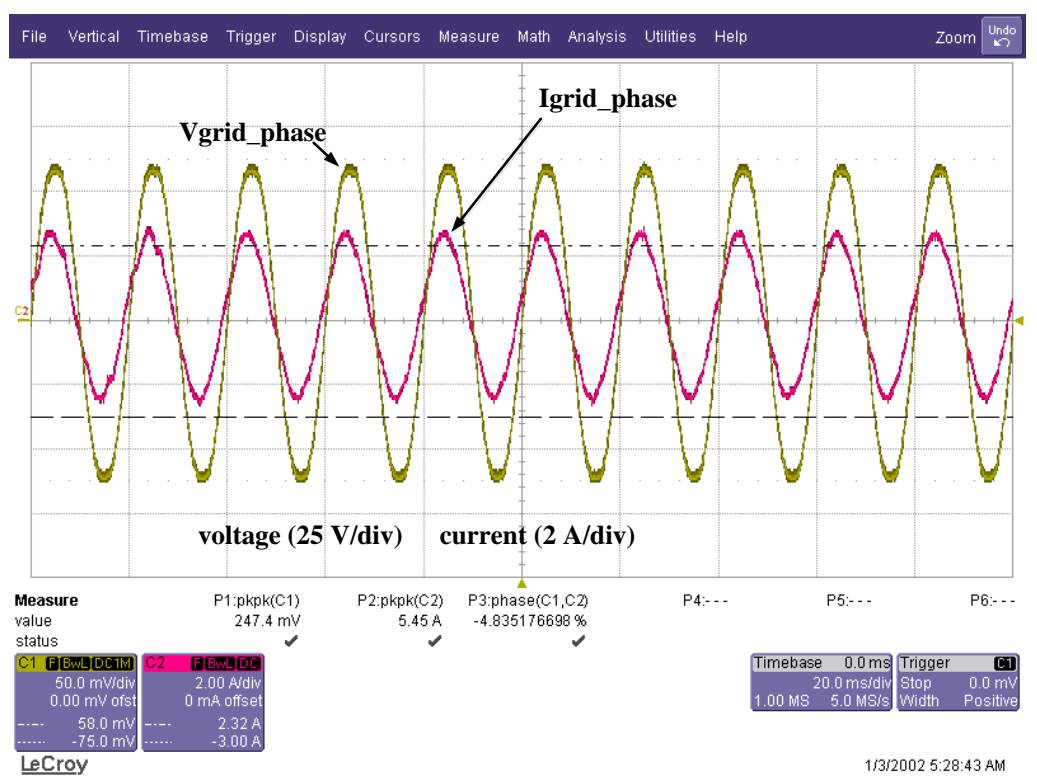

Figure 17. Grid phase voltage (25V/div) at $60 \mathrm{~V}_{\mathrm{pk}}$ and current $(2 \mathrm{~A} / \mathrm{div})$ in grid-connected mode

\section{CONCLUSION}

The paper presents the design and development of the grid-connected quasi-Z-source PV inverter system. The qZSI inverter system has an advantage over the conventional VSI of boosting the lower PV voltage to higher level DC link for connecting with the grid. The voltage and current control of the inverter to achieve a balance power transfer is modelled and analysed to achieve stability and good dynamic response. A description on the PLL technique use for synchronization with the grid is also presented. Verification with both simulation at $5 \mathrm{~kW}$ power level and lab scale experiment at $0.5 \mathrm{~kW}$ is carried out and based on the results, all the controllers work satisfactorily and the inverter integrate well with the grid to supply the obtained power from the PV source. A verification on the inverter performance in complying with the gridconnection standard for distributed generation system will be conducted in the future works.

\section{ACKNOWLEDGEMENTS}

The author would like to thank the Universiti Teknikal Malaysia Melaka for supporting this work under research grant PJP/2015/FKE(10B)/S01447.

\section{REFERENCES}

[1] F. Z. Peng, "Z-source inverter," in Industry Applications Conference, 2002. 37th IAS Annual Meeting. Conference Record of the, 2002, pp. 775-781 vol.2.

[2] Anderson, J. \& Peng, F.Z. 2008, "Four quasi-Z-Source inverters", PESC Record - IEEE Annual Power Electronics Specialists Conference, pp. 2743.

[3] Liu, J., Jiang, S., Cao, D., Lu, X. \& Peng, F.Z. 2011, "Sliding-mode control of quasi-Z-source inverter with battery for renewable energy system", IEEE Energy Conversion Congress and Exposition: Energy Conversion Innovation for a Clean Energy Future, ECCE 2011, Proceedings, pp. 3665.

[4] Li, Y., Jiang, S., Cintron-Rivera, J.G. \& Peng, F.Z. 2013, "Modeling and control of quasi-z-source inverter for distributed generation applications", IEEE Transactions on Industrial Electronics, vol. 60, no. 4, pp. 1532-154.

[5] H. Abu-Rub, A. Iqbal, S. Moin Ahmed, F. Z. Peng, Y. Li, and G. Baoming, "Quasi-Z-source inverter-based photovoltaic generation system with maximum power tracking control using ANFIS," IEEE Trans. Sustainable Energy, vol. 4, no. 1, pp. 11-20, Jan. 2013.

[6] Y. Liu, B. Ge, H. Abu-Rub and F. Z. Peng, "An Effective Control Method for Quasi-Z-Source Cascade Multilevel Inverter-Based Grid-Tie Single-Phase Photovoltaic Power System," in IEEE Transactions on Industrial Informatics, vol. 10, no. 1, pp. 399-407, Feb. 2014.

[7] U. K. Shinde, S. G. Kadwane, S. P. Gawande, M. J. B. Reddy and D. K. Mohanta, "Sliding Mode Control of Single-Phase Grid-Connected Quasi-Z-Source Inverter," in IEEE Access, vol. 5, pp. 10232-10240, 2017.

[8] Y. Liu, B. Ge, H. Abu-Rub and H. Sun, "Hybrid Pulsewidth Modulated Single-Phase Quasi-Z-Source Grid-Tie Photovoltaic Power System," in IEEE Transactions on Industrial Informatics, vol. 12, no. 2, pp. 621-632, April 2016. 
[9] Li, Y., Anderson, J., Peng, F.Z. \& Dichen, L. 2009, "Quasi-z-source inverter for photovoltaic power generation systems", Conference Proceedings - IEEE Applied Power Electronics Conference and Exposition - APEC, pp. 918.

[10] Park, J.-., Kim, H.-., Nho, E.-., Chun, T.-. \& Choi, J. 2009, "Grid-connected pv system using a quasi-z-source inverter", Conference Proceedings - IEEE Applied Power Electronics Conference and Exposition - APEC, pp. 925.

[11] Park, J.-., Kim, H.-., Nho, E.-. \& Chun, T.-. 2010, "Capacitor voltage control for MPPT range expansion and efficiency improvement of grid-connected Quasi Z-Source Inverter", 2010 International Power Electronics Conference - ECCE Asia -, IPEC 2010, pp. 927.

[12] Li, Y., Peng, F.Z., Cintron-Rivera, J.G. \& Jiang, S. 2010, "Controller design for quasi-Z-source inverter in photovoltaic systems", 2010 IEEE Energy Conversion Congress and Exposition, ECCE 2010 - Proceedings, pp. 3187.

[13] Li, Y., Jiang, S., Cintron-Rivera, J.G. \& Peng, F.Z. 2013, "Modeling and control of quasi-z-source inverter for distributed generation applications", IEEE Transactions on Industrial Electronics, vol. 60, no. 4, pp. 1532-154.

[14] Chun, T.W., Lee, H.H., Kim, H.G. \& Nho, E.C. 2011, "Power control for a PV generation system using a singlephase grid-connected quasi Z-source inverter", 8th International Conference on Power Electronics - ECCE Asia: "Green World with Power Electronics", ICPE 2011-ECCE Asia, pp. 889.

[15] H. Akagi, "Instantaneous Power Theory and Applications to Power Conditioning," New Jersey, IEEE Press, 2007.

[16] Kaura, V. \& Blasko, V. 1997, "Operation of a phase locked loop system under distorted utility conditions", IEEE Transactions on Industry Applications, vol. 33, no. 1, pp. 58-63. 